\title{
A.O. Степнов
}

\section{УЧЕНЫЕ Г. ТОМСКА - ЛАУРЕАТЫ СТАЛИНСКОЙ ПРЕМИИ В ОБЛАСТИ НАУКИ ЗА ДОСТИЖЕНИЯ В ПЕРИОД ВЕЛИКОЙ ОТЕЧЕСТВЕННОЙ ВОЙНЫ 1941-1945 гГ.}

\begin{abstract}
На материалах официальной документации, периодической печати и источников личного происхождения рассматривается Сталинская премия в области науки как маркер достижений ученых Томска, местных и эвакуированных в этот город, периода Великой Отечественной войны. Это 14 ученых, получивших премии с 1942 по 1950 г. Освещаются научноисследовательский контекст этих достижений, их практическое значение, а также признание «большим» научным сообществом, в том числе за рубежом.

Ключевые слова: Сталинская премия; Томск; научное сообщество; Великая Отечественная война.
\end{abstract}

Комплекс вопросов, выстраиваемых вокруг Сталинской премии, традиционно окружен в некотором роде скандальным ореолом. Как известно, в 1953 г. премия была упразднена. Ее фонд формировался из гонораров И.В. Сталина, поэтому после смерти последнего распоряжение его средствами для премии стало некорректным. В 1966 г. после учреждения аналоговой Государственной премии СССР, «сталинским» лауреатам даже было предложено обменять старую атрибутику. Долгое время сама принадлежность к пантеону ученых, писателей и поэтов, деятелей искусства, отмеченных премией имени человека, противоречивый образ которого дуалистично вбирает в себя и «вождя народов», и тирана, было сопряжено с упреками, недопониманием и даже подозрениями в сервильности.

Особую критику в этом смысле по сей день вызывает номинация по литературе и искусству. Ведь Сталин лично принимал участие в заседаниях комиссии по ее вручениям, и, как вспоминал тот же Симонов, дух этих заседаний подчас не предполагал возражений на вопрос лидера государства «Какие еще будут мнения?» [1. С. 146-147]. Отсюда и наличие «идеологически верных», но мало признанных художественным сообществом, да и читателем, имен.

Обращает на себя внимание и определенная конъюнктурность премии: имена многих лауреатов не известны ни специалистам в области истории науки, литературы и искусств, ни, тем более, широкой аудитории. Встречается мнение, что в эпоху репрессий обладание премией «гарантировало автору неприкосновенность» [2]. Однако имеются биографии, опровергающие его. Так, например, один из первых лауреатов Сталинской премии советский ученыйбаллистик, генерал-майор артиллерии П.А. Гельвих, награжденный премией первой степени с формулировкой «За научные работы: “О рассеивании, вероятности попадания и математическом ожидании числа попадания", опубликованную в 1934 году, “Теоретические основания выработки правил стрельбы”, опубликованную в 1936 году, “Стрельба по быстродвижущимся целям”, оконченную в 1940 году» [3. С. 1], дважды был репрессирован (до и после получения премии). Ниже мы рассмотрим другие примеры присуждения премий ранее осужденным по политическим мотивам ученым.
Вместе с тем среди лауреатов, в том числе и в рассматриваемой в настоящей статье номинации, немало достойных лиц, чьи заслуги и авторитет не вызывают сомнений. Данная премия маркирует их достижения и служит «культурным навигатором - отмеченные ей произведения входили в культурный канон» [2].

Мы подчас склонны недооценивать роль и значение науки СССР в реализации бесспорно грандиозного и во многом беспрецедентного по своим масштабам модернизационного проекта 1930-1940-х гг. Нам еще предстоит дать оценку этому «научному ренессансу», в поле которого для представителей научной мысли Сталинская премия была высшей формой национального признания, а для науки в целом - лакмусовой бумажкой научного прогресса. Потому и реакция на ее вручение всякий раз была резонансной: биографии и интервью лауреатов печатались на страницах союзных и местных газет, вручение сопровождалось характерным «обрядовым» чествованием. Победа ученого всегда означала победу вуза и локального научного сообщества.

В предвоенный период среди ученых Томска премией был отмечен лишь один человек - старейший профессор города, один из крупнейших специалистов в области паровозостроения своего времени, профессор Томского электромеханического института инженеров железнодорожного транспорта Н.И. Карташев.

Военные годы принесли новые перспективы научному сообществу города, который еще в эпоху индустриализации был институционализирован в качестве крупнейшего форпоста научно-практического освоения Сибири. Будущий президент АН СССР С.И. Вавилов еще в 1932 г., во время посещения Томска, отметил, что «основы исследования естественных богатств Сибири заложены томичами» [4. 1932. 14 июня].

Установка на практический, модернизационный аспект сохранялась в сообществе ученых Томска в годы войны как доминирующая. Это определяло то, что научно-образовательный комплекс города, координацию деятельности которого в 1941-1945 гг. осуществлял Томский комитет ученых по содействию промышленности, транспорту и сельскому хозяйству в военное время (ТКУ), был направлен на генерирование и реализацию комплексных научно-практических проектов, требующих контингентного, междисциплинарного участия. 
Стратегическими траекториями развития науки Томска рассматриваемого периода стали, помимо оборонной тематики, поиск и разработка лекарственного сырья, а также местного топлива, организация научной консультации и обслуживания промышленных, в том числе эвакуированных, предприятий, решение проблемы «Урал - Кузбасс», совершенствование методов медицинского обслуживания.

Это предопределило и тематику проводимых исследований. Сразу же отметим, что полученные за годы войны научные результаты имели впечатляющие масштабы, что нашло признание как государства, так и «большого» научного сообщества (в том числе и за рубежом).

Среди ученых г. Томска, в том числе находившихся здесь в эвакуации, разработки и труды которых были отмечены Сталинской премией, насчитывается 14 человек.

Непосредственно в годы войны ее были удостоены 8 ученых, работавших в Томске. В 1942 г. Лауреатами Сталинской премии 2-й степени стали В.Д. Кузнецов и М.А. Большанина «За научный труд “Физика твердого тела”, опубликованный в 1941 году» [5. С. 31]. «Получение Сталинской премии - великая честь, отмечал в своей речи после вручения В.Д. Кузнецов. Для меня это большое событие, смысл которого заключается в том, что наше правительство, несмотря на напряженную борьбу с лютым врагом, отметило деятельность в области таких научных дисциплин, к которым относится физика» [4. 1942. 19 авг.].

Еще в 1932 г. в свет вышел первый том «Физики твердого тела», сразу же получивший широкое признание коллег и открывший новую главу в развитии отечественной физической науки. В законченном в 1941 г. 2-м томе излагалась теория пластичности и прочности кристаллических твердых тел. Фундаментальные теоретические труды профессора В.Д. Кузнецова - основателя томской школы физики твердого тела, в годы Великой Отечественной войны нашли применение и на практике, в частности при выплавке бронестойкой стали.

Работы профессора В.Д. Кузнецова, написанные доступным и легким языком и виртуозно сочетающие в себе высокий научно-теоретический подход и эмпирическую составляющую, пользовались большой популярностью среди инженеров и техников. Свидетельством тому - огромное количество писем, на протяжении многих лет присылавшихся Владимиру Дмитриевичу из самых отдаленных районов страны. Данный аспект биографии профессора зафиксирован в очерке писателя А. Бека, который однажды встретился с Кузнецовым в поезде. Последний тогда признался случайному знакомому, что этими письмами у него заполнено шесть ящиков (11 тыс. писем) и что он мечтает, чтобы в Томск к нему приехал какой-нибудь писатель и «занялся бы этими письмами» [6. С. 7]. В связи с высоким прикладным потенциалом этого фундаментального исследования В.Д. Кузнецов одно время даже ходатайствовал о присвоении ему ученой степени доктора технических наук [7. Л. 89-89 об.].

«Физика твердого тела» определила имя В.Д. Кузнецова в науке и завершила процесс становления его научной школы [8. Л. 104-106]. Отразилось это и в широком признании труда со стороны его коллег, в том числе иностранных. Интерес к книге проявил, например, немецкий профессор из Института Кайзера Вильгельма Полани, который еще в 1930-е гг. предложил перевести ее на немецкий язык и издать в Германии, доктор-инженер, профессор Закс из Франкфурта-на-Майне. На первый том ссылались немецкие ученые Э. фон Шмид и В. Боас в своей вышедшей в 1935 г. монографии «Kristallplastiritat» [7. Л. 14, 15].

В 1943 г. В.Д. Кузнецов закончил работу над 3-м томом. «Предполагалось, что вторым томом будет исчерпана “Физика твердого тела”, - писал он в 1943 г., но перспективы значительно расширились» [9. Л. 19].

В том же году лауреатом Сталинской премии 2-й степени стал А.А. Заварзин - за более раннюю работу «Очерки эволюционной гистологии нервной системы». Подчеркнем, что в 1936-1941 гг. он заведовал кафедрой гистологии в 1-м Ленинградском медицинском институте. После эвакуации в Томск получил должность профессора местного университета. В 1944 г. ему было присвоено звание Почетного члена Ученого совета Томского университета. Здесь Заварзин работал над следующим своим фундаментальным исследованием - «Очерки по эволюционной гистологии крови и соединительной ткани» (начал его в ноябре 1940 г.). Эта монография стала итогом более чем 30летних исследований ученого.

В 1943 г. Сталинская премия (2-й степени) была вручена ученому из Томского индустриального института (ТИИ) К.В. Радугину с формулировкой «За открытие и изучение Усинского месторождения марганцевых руд» [10. С. 8].

Тогда же «За создание щитового метода разработки крутопадающих пластов» Сталинская премия была вручена Н.А. Чинакалу из того же ТИИ. Его щитовое крепление для шахт и система разработки мощных пластов угля были созданы еще в довоенные годы. Прославили же его как ученого они именно во время войны, когда получили широкое практическое применение. Щит Чинакала (такое упрощенное название для прессы получило его изобретение) позволил кардинально усовершенствовать технологии угольной промышленности. Данная конструкция обеспечивала резкое повышение производительности труда без новых капитальных затрат и увеличивала добычу угля (более подробно о данном изобретении см.: [11]).

С лета 1942 г. решением Государственного комитета обороны и Наркомугля началось внедрение щитовой системы в производство, в результате чего удалось снизить потери полезных ископаемых, сократить производственные расходы, повысить безопасность рабочих. Председатель Томского комитета ученых Б.П. Токин не без назидания отметил тогда, что ученым «придется равняться в помощи Кузбассу по Н.А. Чинакалу, который провел такую большую работу» [12. Л. 137].

В том же 1943 г. премии удостоились основатель томской школы синтетических лекарственных препаратов Л.П. Кулев (3-я степень «За разработку метода ускорения технического анализа»), томский профессор-хирург А.Г. Савиных (2-я степень «За работы по 
хирургическому лечению органов средостения, завершенные научным трудом "Чрезбрюшинная медиастинотомия и её практическое значение", законченным в 1942 году»). Усилиями последнего широкое применение в госпиталях получили новаторские хирургические методы, в том числе предложенные Савиных способы хирургического лечения огнестрельных ранений и воспалений задне-нижнего отдела средостения, - ранее эти случаи считались смертельными.

Эвакуированный в Томск из Москвы почтенный профессор-транспортник С.П. Сыромятников в 1943 г. также был отмечен премией 2-й степени «За многолетние выдающиеся работы в области науки и техники» (более подробно о научной деятельности С.П. Сыромятникова и эвакуированного в Томск коллектива Московского электромеханического института инженеров железнодорожного транспорта в годы Великой Отечественной войны см.: [13]).

Как известно, в 1944-1945 гг. Сталинские премии не присуждались: поскольку в предыдущие военные годы почти все лауреаты перечисляли деньги в Фонд обороны, то и фонд премии, по всей вероятности, разумнее посчитали направить на поддержку Красной Армии. Однако в литературе высказываются и иные точки зрения. Так, имеется мнение, что причиной тому послужили идеологические конфликты вокруг журнала «Знамя» (в 1944 г. в нем был назначен новый редактор В. Вишневский), борьба против «политически вредных, враждебных настроений» деятелей советской культуры (Асеева, Зощенко, Сельвинского, Федина, Довженко и др.). Полагается, что именно в этом контексте Сталин принял решение «очередного присуждения премий не проводить», хотя списки за 1943 год были уже подготовлены [14. С. 77-81].

В 1946 г. за работы военных лет лауреатом Сталинской премии 1-й степени с формулировкой «За научный труд "Хирургическая анатомия грудного протока и главных лимфатических коллекторов и узлов туловища" (1945)» стал Д.А. Жданов, в годы войны - заведующий кафедрой нормальной анатомии, директор Томского медицинского института (ТМИ). Тогда же был награжден Б.И. Баяндуров (2-я степень «За научные исследования о влиянии головного мозга на обмен веществ в организме, обобщённые в монографии “Трофическая функция головного мозга”»). Последний считается основателем сибирской физиологической школы и последователем академика Павлова. На протяжении многих лет он совместно со своими учениками изучал влияние головного мозга на трофику различных органов, что получило практическое применение в медицине и сельском хозяйстве [4. 1939. 26 окт.].

Баяндурову же принадлежит идея «прибора для обнаружения металлических включений в теле человека», которая в годы войны была реализована научным сотрудником Сибирского физико-технического института Томского государственного университета (ТГУ) Б.П. Кашкиным и лаборантом ТИИ П.П. Одинцовым. Баяндуров принял участие и в осуществлении крупного междисциплинарного проекта по поиску и разработке лекарственного сырья, который требует особого упоминания (также см.: [15. С. 133-134]).

Впервые летом 1941 г. с инициативой об осуществлении данного проекта выступил заведующий кафедрой фармакогнозии ТМИ В.В. Ревердатто (по совместительству - профессор ТГУ) [16. Л. 3]. Связано это было с нуждами местного фармацевтического завода, который в то время не обладал запасами лекарственного сырья «даже на текущий квартал».

Дело в том, что в довоенный период вся фармацевтическая промышленность СССР использовала лекарственное сырье, ввозившееся из Украины, с побережья Черного моря, из Ленинградской области. Наркомздрав в те годы руководствовался представлением о нерациональности использования лекарственных культур Сибири. Несмотря на то что дикорастущая флора Западной Сибири была очень разнообразна, например, Томский фармацевтический завод ввозил из европейской части СССР лекарственные травы, «обильно произрастающие на севере Новосибирской области».

В результате в первые же месяцы войны «основная масса плантаций лекарственных растений и большая часть предприятий фармпромышленности оказались во временно оккупированной или прифронтовой полосе» [17. Л. 96-97].

План «применения дико произрастающих в Сибири лекарственных растений взамен ранее импортируемых и ввозимых» был предложен коллективами ботанических кафедр, Ботанического сада и Гербария ТГУ и базировался на наработках сибирской научной ботанической школы, основателем которой был профессор П.Н. Крылов. Последний при жизни начал издание многотомного труда «Флора Западной Сибири», работу над которым продолжили его ученики, прежде всего его преемница заведующая Гербарием ТГУ доцент Л.П. Сергиевская. Местным ботаникам было известно, что в Сибири тогда произрастало около 150 видов растений, обладающих лекарственными свойствами.

Инициатива нашла одобрение Комитета, и вскоре при нем было создано ботанико-фармакологическое бюро (позднее реорганизовано в медико-биологическое) для реализации проекта «по замене импортных лекарственных растений, их исследованию, сбору и снабжению ими гражданских и военных лечебных учреждений», к которому привлекались ботаники, химики, фармакологи и физиологи местных и эвакуированных (например, Б.И. Лаврентьев из Всесоюзного института экспериментальной медицины) вузов и НИИ.

В состав бюро вошли В.В. Ревердатто, профессорфармаколог ТМИ Н.В. Вершинин, директор Ботанического сада А.Д. Бейкина (они составляли так называемую руководящую тройку), а также Л.П. Сергиевская, профессор-ботаник К.Т. Сухоруков, профессорфизиолог Б.И. Баяндуров, доцент ТМИ Л.Н. Дьяконова-Шульц, Н.Ф. Гофштадт и др. [18. С. 228-230].

Ученым удалось в сжатые сроки организовать сбор и заготовку местного лекарственного растительного сырья. Собирались не только растения в окрестностях Томска, но и, при помощи Новосибирской 
конторы Лекартреста, произрастающие на Алтае и в Хакассии, в Саянах и степной полосе Сибири [19. Л. 74].

Параллельно осуществлялся и фармакологический проект, руководил которым профессор ТМИ Н.В. Вершинин. Еще в 1934 г. он совместно с коллективами кафедры фармакологии ТМИ и Новосибирским камфорным заводом впервые осуществил синтез левовращающей камфары из пихтового масла методом дегидрирования борнеола [20. С. 128]. Благодаря этому удалось доказать большую эффективность сибирской камфары в сравнении с японской, от импорта которой СССР отказался уже в 1936 г.

В годы войны исследования в этом направлении были актуализированы, и Н.В. Вершинин вместе с эвакуированным в Томск профессором-химиком В.А. Измаильским открыл способ замены импортной базиликовой камфары. Были проведены экспериментальные испытания в лабораторных условиях, после чего препарат был внедрен в медицинскую практику [21. С. 163].

Экспериментальное апробирование полученных препаратов на животных осуществлялось под руководством профессора Баяндурова. Терапевтическую апробацию проводил профессор Д.Д. Яблоков.

В итоге был заложен фундамент для формирования капитальной базы местного лекарственного сырья и значительного усиления фармацевтической промышленности региона [22. Л. 1-1 об.]. Уже к началу 1942 г. кластер ученых города, объединенных вокруг импортозамещения лекарственного сырья, сохранив установку на изыскание заменителей имеющихся и создание новых лекарственных веществ, поставил перед собой задачу обслуживать и помогать «хозяйственным организациям по использованию растительных ресурсов области для всей фармацевтической промышленности СССР» [23. Л. 147]. В январе 1942 г. Новосибирский обком ВКП(б) дал поручение ТКУ составить проект деятельности по лекарственному сырью в двух вариантах: «С расчетом обеспечения потребностей Новосибирской области исключительно местным лекарственным сырьем и с расчетом обеспечения сибирским лексырьем всей фармпромышленности СССР» [12. Л. 59-59 об.].

В 1943 г. Комитет ученых поставил вопрос о созыве всесоюзного совещания по лекарственному растительному сырью в Томске. Сибирская межобластная конференция по лекарственному растительному сырью состоялась 3 апреля 1944 г. В ней приняли участие медики и ботаники Новосибирска, Иркутска, Омска, Хабаровска, Ойрот-Туры, Барнаула, Свердловска, представители Наркомздрава СССР, Всесоюзного института лекарственных растений и других организаций. Конференция продлилась 3 дня. Было заслушано 25 докладов [4. 1944. 18 марта].

Данное мероприятие стало этапом институционализации нового стратегического научного направления. К моменту его проведения Ученый совет Наркомздрава и Государственный комитет по фармакопее уже приняли целый ряд предложений томских ученых по новым лекарственным растениям. Томск усилиями местного научного сообщества стал центром зарождения независимой от импорта фармацевтической промышленности Сибири.

В 1947 г. Н.В. Вершинин, В.В. Ревердаттто и Д.Д. Яблоков «За изучение новых лекарственных растений, получение из них лечебных препаратов и внедрение их в практику здравоохранения» получили звания лауреатов Сталинской премии 2-й степени. Данный проект на длительное время стал драйвером развития научных исследований в ботанике и фармакологии, физиологии и лечебной практике.

Наконец, в 1950 г. «За научный труд “Фитонциды”» Сталинской премии 3-й степени был удостоен Б.П. Токин. Его монография «Бактерициды растительного происхождения (фитонциды)», впервые опубликованная в Томске в 1942 г., стала результатом многолетних творческих поисков ученого. Теоретикопрактическое значение этого открытия сразу получило высокие отзывы его коллег: А.А. Заварзина, Б.И. Лаврентьева, Д.Д. Яблокова, И.В. Торопцева, П.С. Купалова и др.

Тогда во многих зарубежных странах, прежде всего в США, задача поисков антисептиков растительного происхождения была актуальной [24. С. 4]. В том числе и поэтому в сентябре 1942 г. жена премьерминистра Великобритании Черчилля, председатель фонда Красного Креста «Помощь России» Клементина Черчилль обратилась к председателю Томского комитета ученых с просьбой сообщить ей подробности о «новом замечательном средстве» [4. 1942. 17 сент.].

К слову, в литературе имеется мнение (Л.А. Орбели, Н.Н. Бурденко, Б.Л. Исаченко и др.), что Токин должен считаться автором открытия не только фитонцидов высших растений, но и антибиотиков в целом [21. С. 426]. Отметим и то, что впервые Борис Петрович был выдвинут на Сталинскую премию в том же 1942 г.

ТКУ оценивал научные достижения и ряда других ученых, таких как математик Н.П. Романов [12. Л. 139 об.], физик Г.М. Кондратьев [25. Л. 248], выдвигая их на Сталинскую премию.

Немного о политическом аспекте. Среди перечисленных лауреатов двое ранее были репрессированы и имели в связи с этим не самое удобное для тех лет пятно в биографии. В 1928 г. по «Шахтинскому делу» был репрессирован и осужден на 6 лет строго режима Н.А. Чинакал [26]. Именно по этой причине его дальнейшая жизнь оказалась связанной с Сибирью (до этого его инженерная и научно-исследовательская деятельность была сосредоточена в шахтах Донбасса).

Б.П. Токин, который в 1936-1937 гг. являлся директором ТГУ, был отстранен от этой должности приказом наркома просвещения РСФСР А.С. Бубнова и вскоре после этого по многочисленным обвинениям (вредительство на посту директора университета, порочащие связи, бывшее членство в партии эсеров и т.д.) был исключен из партии, а в феврале 1938 г. и вовсе арестован. Пробыв в тюрьме ровно год, он был освобожден «за прекращением дела» [27. С. 36-42].

В.В. Ревердатто в 1935 г. при проверке документов был исключен из рядов ВКП(б) как «выходец из классово-враждебной среды». Восстановлен в ней 
он был только в 1946 г. (хотя в 1951 г. исключен вновь) [21. С. 369].

Данные биографические факты позволяют нам сделать вывод, что ключевым критерием отбора лауреатов премии по преимуществу были «чистые» научные достижения, но не демонстрация лояльности и наличие «кристальной» партийной биографии.

Обладание премией, бесспорно, занимало важное место в профессиональном бытии ученых. Она выступила одним из краеугольных атрибутов успеха и признания - того, что П. Бурдье называл «символическим капиталом». К примеру, профессор В.Д. Кузнецов подчас не отказывал себе в удовольствии в направляемых в различные инстанции письмах подписывать себя как «Лауреат Сталинской премии» [7. Л. 89 об.]. Имели место и привилегии, дававшиеся вместе со званием (более подробно см.: [28. С. 135]). К тому же номинал премии варьировался от 50 (2-я ст.) до 100 (1-я ст.) тыс. руб. в 1941 г., от 100 (2-я ст.) до 200 (1-я ст.) тыс. руб. в 1942-1943 гг. и от 50 (3-я ст.) до 200 (1-я ст.) тыс. руб. в послевоенные годы, что в те времена составляло, скажем так, немалую сумму.

В заключение вновь отметим, что изучение истории присуждений Сталинской премии важно для нас в том отношении, что в рассматриваемый период она выступала одним из ключевых маркеров динамики научного прогресса. По всей видимости, в силу факторов ментального характера, влияния академической традиции города Томска в годы Великой Отечественной войны здесь наблюдался всплеск научно-исследовательской активности, зарождались новые научные направления. Данное сочетание времени и места стало важной вехой в научных биографиях целого ряда ученых.

\section{ЛИТЕРАТУРА}

1. Симонов К.М. Глазами человека моего поколения : Размышления о И.В. Сталине. М. : Книга, 1990. 253 с.

2. Венявкин И. Краткий путеводитель по Сталинской премии : Главная литературная СССР : рекордсмены, скандалы и курьезы // Онлайнуниверситет Arzamas. URL: https://arzamas.academy/materials/978 (дата обращения 13.02.2018).

3. Постановление СНК СССР «О присуждении Сталинских премий за выдающиеся работы в области науки» от 13 марта 1941 года // Вестник АН СССР. 1941. № 4. С. 1-6.

4. Красное знамя. Орган Томского горкома ВКП(б) и Городского совета депутатов трудящихся (с августа 1944 г. - Томского обкома ВКП(б) и Областного совета депутатов трудящихся). Томск.

5. Постановление СНК СССР «О присуждении Сталинских премий за выдающиеся работы в области науки» от 10 апреля 1942 года // Вестник АН СССР. 1942. № 4. С. 31-35.

6. Встреча в вагоне // Бек. А.А. Зерно стали: рассказы и очерки. М. : Профиздат, 1950. 182 с.

7. Государственный архив Томской области (далее ГАТО). Ф. 1562. Оп. 1. Д. 700.

8. Костерев А.Г. Научная биография академика В.Д. Кузнецова : дис... канд. ист. наук. Томск, 2008.215 л.

9. ГАТО. Ф. Р-1562. Оп. 1. Д. 489.

10. Постановление СНК СССР «О присуждении Сталинских премий за выдающиеся работы в области науки» от 22 марта 1943 года // Вестник АН СССР. 1943. № 3. С. 6-13.

11. Степнов А.О. Томский комитет ученых и помощь Кузбассу в годы Великой Отечественной войны // Великая Отечественная война : исторические уроки и современность (70-летию Великой Победы посвящается) : сб. материалов Всерос. науч.-практ. конф. с междунар. участием «Великая Отечественная война : исторические уроки и современность (70-летию Великой Победы посвящается)» г. Иваново, 2 апреля 2015 г. Иваново: ИРОИО, 2015. С. 62-64.

12. Центр документации новейшей истории Томской области (далее ЦДНИ ТО). Ф. 1078. Оп. 1. Д. 10.

13. Степнов А.О. Томский комитет ученых и проблемы работы транспорта в годы Великой Отечественной войны $1941-1945$ гг. // Сибирь в Великой Отечественной войне: сб. материалов Всерос. науч. конф., посв. 70-летию Победы советского народы в Великой Отечественной войне (Новосибирск, 27-28 апреля 2015 г.). Новосибирск : Институт истории СО РАН, Параллель, 2015. С. 332-339.

14. Сталинские премии. Две стороны одной медали : сб. документов и художественно-публицистических материалов / сост. В.Ф. Свиньин, К.А. Осеев. Новосибирск : «Свиньин и сыновья», $2007.880 \mathrm{c.}$

15. Некрылов С.А., Фоминых С.Ф., Степнов А.О. Наука и практическая медицина г. Томска в годы Великой Отечественной войны // Сибирский медицинский журнал. 2014. Т. 29, № 3. С. 131-138.

16. ЦДНИ ТО. Ф. 1078. Оп. 1. Д. 2.

17. ЦДНИ ТО. Ф. 1078. Оп. 1. Д. 12

18. Томский комитет ученых в годы Великой Отечественной войны 1941-1945 гг. : документы и материалы / отв. ред. С.Ф. Фоминых. Томск : Издательский Дом ТГУ, 2015. 480 с.

19. ЦДНИ ТО. Ф. 1078. Оп. 1. Д. 6.

20. Профессора медицинского факультета Императорского (государственного) Томского университета - Томского медицинского института Сибирского государственного медицинского университета (1878-2003) : Биографический словарь. Томск : Изд-во Том. ун-та, 2004. T. 2. 402 c.

21. Профессора Томского университета : биографический словарь / С.Ф. Фоминых, С.А. Некрылов, Л.Л. Берцун, А.В. Литвинов. Томск : Изд-во Том. ун-та, 1998. Т. 2. 544 с.

22. ЦДНИ ТО. Ф. 1078. Оп. 2. Д. 1.

23. ЦДНИ ТО. Ф. 1078. Оп. 1. Д. 9.

24. Фитонциды. Научные исследования, доложенные на конференции по проблемам антисептиков биологического происхождения (Томск, 14-15 февраля 1944 г.). Томск : Красное знамя, 1944. 288 с.

25. ЦДНИ ТО. Ф.1078. Оп.1. Д. 4.

26. Зворыгин Л.В. Инженер, горняк, педагог, ученый: к 110-летию со дня рождения Николая Андреевича Чинакала // «Наука в Сибири». 1998. № 43-44. URL: http://www.nsc.ru/HBC/hbc.phtml?3+196+1 (дата обращения 16.04.2017).

27. Степнов A.O. Томский период жизни и творчества профессора Б.П. Токина : научная биография. Saarbrücken, Germany : Изд-во LAP LAMBERT Academic Publishing GmbH \& Co. KG, 2015. 93 c.

28. Фоминых С.Ф., Степнов А.О. Повседневность ученых г. Томска в годы Великой Отечественной войны 1941-1945 гг. // Вестник Томского государственного университета. 2016. № 412. С. 132-142.

Статья представлена научной редакцией «История» 19 февраля 2018 г. 


\section{TOMSK SCIENTISTS - STALIN PRIZE WINNERS IN THE FIELD OF SCIENCE FOR THEIR ACHIEVEMENTS DURING THE GREAT PATRIOTIC WAR (1941-1945)}

Vestnik Tomskogo gosudarstvennogo universiteta - Tomsk State University Journal, 2018, 430, 132-138. DOI: $10.17223 / 15617793 / 430 / 18$

Aleksey.O. Stepnov, Tomsk State University (Tomsk, Russian Federation). E-mail: ASAOM@yandex.ru Keywords: Stalin Prize; Tomsk; scientific community; Great Patriotic War.

In the article, on the materials of official documents, periodicals and personal sources, the achievements of Tomsk scientists in the field of science during the Great Patriotic War that were marked with the Stalin Prize are considered. The perception of this award and its criticism for conjuncture and prejudice in the selection of winners are highlighted. Nevertheless, there was a high symbolic significance of the Stalin Prize. It was the highest form of national recognition for the soviet scientists during the modernisation and the "scientific Renaissance" of the 1930s-1940s, and it was the litmus test of scientific progress in the USSR. From 1942 to 1950, 14 scientists of Tomsk, some of whom were in this city in evacuation, were awarded the Stalin Prize for research achievements during the Great Patriotic War. Eight scientists (physicists V.D. Kuznetsov, M.A. Bolshanina, chemist L.P. Kulev, surgeon A.G. Savinykh, specialist in locomotive construction S.P. Syromyatnikov, histologist A.A. Zavarzin, geologist K.V. Radugin, specialist in mining N.A. Chynacal) in 1942 and 1943, and six scientists were awarded during the postwar years (surgeon D.A. Zhdanov, physiologist B.I. Bayandurov, pharmacologist N.I. Vershinin, botanist V.V. Reverdatto, therapist D.D. Yablokov, biologist B.P. Tokin). Their activities were integrated into the strategic directions chosen and coordinated by the Tomsk Committee of Scientists: research and development of medicinal raw materials, mineral deposits in Siberia, organisation of consultations and scientific support of industrial enterprises, solution to the "Ural-Kuzbass" problem, etc. The scientific context of the discoveries and works that were awarded and their practical application (introduction into industry, medical practice, transport, etc.) are analysed. The perception of these achievements by other scientists, the "large" scientific community, including international recognition, is reflected. The influence of political aspects on the selection of winners is considered. It is concluded that the Stalin Prize in the field of science during the period under review representatively reflected the main achievements of scientists, and it was a marker of research development, including on a regional scale. It is emphasised that, taking into account the impressive monetary value of this award and the privileges accompanying the title, the Stalin Prize was an important part of the "symbolic capital" of the soviet scientist during the Stalin era.

\section{REFERENCES}

1. Simonov, K.M. (1990) Glazami cheloveka moego pokoleniya: Razmyshleniya o I.V. Staline [With the eyes of a person of my generation: Reflections on I.V. Stalin]. Moscow: Kniga.

2. Venyavkin, I. (n.d.) Kratkiy putevoditel' po Stalinskoy premii: Glavnaya literaturnaya nagrada SSSR: rekordsmeny, skandaly i kur'ezy [A short guide to the Stalin Prize: The main literary prize of the USSR: record holders, scandals and curiosities]. [Online] Available from: https://arzamas.academy/materials/978. (Accessed 13.02.2018).

3. Vestnik AN SSSR. (1941) Postanovlenie SNK SSSR “O prisuzhdenii Stalinskikh premiy za vydayushchiesya raboty v oblasti nauki” ot 13 marta 1941 goda [Decree of the Council of People's Commissars of the USSR “On awarding the Stalin Prizes for outstanding work in the field of science" of March 13, 1941]. Vestnik AN SSSR. 4. pp. 1-6.

4. Krasnoe znamya.

5. Vestnik AN SSSR. (1942) Postanovlenie SNK SSSR “O prisuzhdenii Stalinskikh premiy za vydayushchiesya raboty v oblasti nauki” ot 10 aprelya 1942 goda [Resolution of the Council of People's Commissars of the USSR “On awarding the Stalin Prizes for outstanding work in the field of science" of April 10, 1942]. Vestnik AN SSSR. 4. pp. 31-35.

6. Bek, A.A. (1950) Vstrecha v vagone [Meeting in the rail car]. In: Zerno stali: rasskazy i ocherki [Grain of steel: stories and essays]. Moscow: Profizdat.

7. State Archive of Tomsk Oblast (GATO). Fund 1562. List 1. File 700. (In Russian).

8. Kosterev, A.G. (2008) Nauchnaya biografiya akademika V.D. Kuznetsova [Scientific biography of Academician V.D. Kuznetsov]. History Cand. Diss. Tomsk, 2151.

9. State Archive of Tomsk Oblast (GATO). Fund R-1562. List 1. File 489. (In Russian).

10. Vestnik AN SSSR. (1943) Postanovlenie SNK SSSR “O prisuzhdenii Stalinskikh premiy za vydayushchiesya raboty v oblasti nauki” ot 22 marta 1943 goda [Decree of the Council of People's Commissars of the USSR "On awarding the Stalin Prize for outstanding work in the field of science" of March 22, 1943]. Vestnik AN SSSR. 3. pp. 6-13.

11. Stepnov, A.O. (2015) [Tomsk Committee of Scientists and Assistance to Kuzbass during the Great Patriotic War]. Velikaya Otechestvennaya voyna: istoricheskie uroki i sovremennost' (70-letiyu Velikoy Pobedy posvyashchaetsya) [The Great Patriotic War: Historical Lessons and Modernity (dedicated to the 70th anniversary of the Great Victory)]. Proceedings of the all-Russian conference. Ivanovo. 2 April 2015. Ivanovo: IROIO. pp. 62-64. (In Russian).

12. Documentation Center of the Modern History of Tomsk Oblast (TsDNI TO). Fund 1078. List 1. File 10. (In Russian).

13. Stepnov, A.O. (2015) [Tomsk Committee of Scientists and the problems of transport in the years of the Great Patriotic War of 1941-1945]. Sibir' $v$ Velikoy Otechestvennoy voyne [Siberia in the Great Patriotic War]. Proceedings of the all-Russian conference on the 70th anniversary of the Victory of the Soviet people in the Great Patriotic War. Novosibirsk. April 27-28, 2015. Novosibirsk: Institute of History, SB RAS, Parallel'. pp. 332-339. (In Russian).

14. Svin'in, V.F. \& Oseev, K.A. (eds) (2007) Stalinskie premii. Dve storony odnoy medali: sb. dokumentov i khudozhestvenno-publitsisticheskikh materialov [The Stalin Prize. Two sides of the same coin: documents and artistic and journalistic materials]. Novosibirsk: "Svin'in i synov'ya".

15. Nekrylov, S.A., Fominykh, S.F. \& Stepnov, A.O. (2014) Science and practical medicine of Tomsk during the Great Patriotic War. Sibirskiy meditsinskiy zhurnal - Siberian Medical Journal. 29:3. pp. 131-138. (In Russian).

16. Documentation Center of the Modern History of Tomsk Oblast (TsDNI TO). Fund 1078. List 1. File 2. (In Russian).

17. Documentation Center of the Modern History of Tomsk Oblast (TsDNI TO). Fund 1078. List 1. File 12. (In Russian).

18. Fominykh, S.F. (ed.) (2015) Tomskiy komitet uchenykh v gody Velikoy Otechestvennoy voyny 1941-1945 gg.: dokumenty i materialy [Tomsk Committee of Scientists during the Great Patriotic War of 1941-1945: documents and materials]. Tomsk: Tomsk State University.

19. Documentation Center of the Modern History of Tomsk Oblast (TsDNI TO). Fund 1078. List 1. File 6. (In Russian).

20. Fominykh. S.F. (ed.) (2004) Professora meditsinskogo fakul'teta Imperatorskogo (gosudarstvennogo) Tomskogo universiteta - Tomskogo meditsinskogo instituta - Sibirskogo gosudarstvennogo meditsinskogo universiteta (1878-2003): Biograficheskiy slovar' [Professor of the Medical Faculty of the Imperial (State) Tomsk University - Tomsk Medical Institute - Siberian State Medical University (1878-2003): A biographical dictionary]. Vol. 2. Tomsk: Tomsk State University.

21. Fominykh. S.F. et al. (1998) Professora Tomskogo universiteta: biograficheskiy slovar' [Professors of Tomsk University: A biographical dictionary]. Vol. 2. Tomsk: Tomsk State University. 
22. Documentation Center of the Modern History of Tomsk Oblast (TsDNI TO). Fund 1078. List 2. File 1. (In Russian).

23. Documentation Center of the Modern History of Tomsk Oblast (TsDNI TO). Fund 1078. List 1. File 9. (In Russian).

24. Krasnoe znamya. (1944) Fitontsidy. Nauchnye issledovaniya, dolozhennye na konferentsii po problemam antiseptikov biologicheskogo proiskhozhdeniya (Tomsk, 14-15 fevralya 1944 g.) [Phytoncides. Scientific research, reported at a conference on the problems of antiseptics of biological origin (Tomsk, February 14-15, 1944)]. Tomsk: Krasnoe znamya.

25. Documentation Center of the Modern History of Tomsk Oblast (TsDNI TO). Fund 1078. List 1. File 4. (In Russian).

26. Zvorygin, L.V. (1998) Inzhener, gornyak, pedagog, uchenyy: k 110-letiyu so dnya rozhdeniya Nikolaya Andreevicha Chinakala [Engineer, miner, teacher, scientist: to the 110th anniversary of the birth of Nikolai Andreevich Chinakal]. Nauka v Sibiri. 43-44. [Online] Available from: http://www.nsc.ru/HBC/hbc.phtml?3+196+1. (Accessed 16.04.2017).

27. Stepnov, A.O. (2015) Tomskiy period zhizni i tvorchestva professora B.P. Tokina: nauchnaya biografiya [The Tomsk period of life and work of Professor BP. Tokin: a scientific biography]. Saarbrücken, Germany: Izd-vo LAP LAMBERT Academic Publishing GmbH \& Co. KG.

28. Fominykh, S.F. \& Stepnov, A.O. (2016) Daily life of Tomsk scholars during the Great Patriotic War. (1941-1945). Vestnik Tomskogo gosudarstvennogo universiteta - Tomsk State University Journal. 412. pp. 132-142. (In Russian). DOI: $10.17223 / 15617793 / 412 / 22$

Received: 19 February 2018 